\title{
Advancement of TDR Technique for Locating Power Cable Insulation Degradation
}

\author{
Tze Mei Kuan", Azrul Mohd. Ariffin", Maria Madelina Bemmynser Sedau ${ }^{\#}$ \\ Department of Electrical Power Engineering, Universiti Tenaga Nasional, Jalan IKRAM-UNITEN, 43000 Kajang, Selangor, Malaysia \\ E-mail:tzemei@uniten.edu.my,azrula@uniten.edu.my,maria.madelina@gmail.com
}

\begin{abstract}
This paper discusses the advancement of time domain reflectometry (TDR) technique for locating degradation in power cable insulation with and without jointing. TDR technique is commonly used for localizing processes in various fields. It applies the concept of radar where a signal propagates through a medium will be reflected when there is an impedance mismatch. However, the application of TDR technique in power cable is still limited and its potential to pinpoint the exact location of degradation in power cables is to be ascertained. This study conducts experiments to investigate the potential of this technique in pinpointing the location of degradation in power cable with and without jointing. Experiments are conducted on un-degraded cable without any joint and followed by cable with jointing up to 2 cable joints. For experiments with jointing, the un-degraded cable is sectionalized into 2 parts, and one of the sections is replaced by a degraded cable. Experiments are repeated by sectionalizing the un-degraded cable into 3 parts, and each section is replaced with a degraded cable up to 2 sections. TDR results from all experiments are compiled and then analyzed. The results obtained from this study have proven that TDR technique is capable of identifying the degradation along a cable and at the same time pinpointing the exact location of degraded cable section.
\end{abstract}

Keywords — cable defects; cable insulation; cable joints; time domain reflectometry

\section{INTRODUCTION}

The power cable is an important medium in transmitting electricity from the generation to transmission and distributing to end users. Power utility companies hold huge responsibility in ensuring the reliability of these power cables. Any defect in the power cable that is not taken care of may lead to power cable failure causing major electricity disruption which not only brings losses to the industries financially but also lives are of concern. Therefore, there is a need for a technique which is able to assist the power utility companies in power cable maintenance works to provide a more reliable power system network.

Studies in [1]-[7] have suggested a number of techniques which are currently in used to prevent power cables from failing. However, there are still numerous reports of electricity disruption due to power cable failure [8]-[16]. In addition, a study in [17] mentioned that the techniques in [1]-[7] are either destructive, can only be conducted in laboratory or lack of capability to predict the future performance of the cable. Hence, the study [17] suggested reflectometry techniques instead due to its non-destructive nature of electrical cable diagnostics. One of the

This project is funded by the Ministry of Education, Malaysia under the Fundamental Research Grant Scheme (20140121FRGS) reflectometry techniques mentioned is the time domain reflectometry (TDR) technique.

Reflectometry techniques are mainly categorized into three which are the time domain reflectometry (TDR), frequency domain reflectometry (FDR) and joint timefrequency domain reflectometry (JTFDR) techniques. Studies in [18]-[19] have favored the JTFDR due to its good resolution and accuracy in detecting faults in the cables. However, JTFDR's main disadvantage is the limitation of cable length. JTFDR is only suitable for cable length shorter than $100 \mathrm{~m}$ which is a major setback for power utility companies where most of the cables installed are more than $100 \mathrm{~m}$ in length. On the other hand, FDR which also provides good resolution for longer length cables is not considered in this study as FDR incurs a higher cost and the types of the faults cannot be exactly distinguished [19].

A study in [19] also suggested that TDR is an easy technique to be applied, and reflections are easily detected, but it is not suitable for short cables, which is an advantage in this scenario. TDR is said to have poor resolution compared to JTFDR and FDR [19] however, results in this study have proven otherwise. A number of experiments are conducted on XLPE cables with and without jointing to evaluate the potential of TDR technique to locate degraded insulation along these cables. 


\section{MATERIAL AND METHOD}

This study comprises of experimental verification of TDR technique in detecting cable insulation degradation along XLPE cable with and without jointing. Cables used in this study are $240 \mathrm{~mm}^{2} 11 \mathrm{kV}$ XLPE unarmoured cables with lengths of $100 \mathrm{~m}, 200 \mathrm{~m}$, and $300 \mathrm{~m}$.

Since this research uses cables with different lengths, different cable insulation condition and jointing, hence a number of cable configurations with these parameters can be constructed. Thus, this research is divided into 3 parts. Part 1 involves experiments of good and degraded cables with different lengths without any cable jointing while part 2 looks into the combination of 2 different cable lengths with 1 degraded cable section and a single good joint.

Part 3 studies the effect of 2 good cable joints with 1 and 2 degraded sections out of the combination of three $100 \mathrm{~m}$ length cables. Cable configurations of experiments in part 1, part 2 and part 3 are illustrated in Fig. 1, Fig. 2 and Fig. 3, respectively. Table I, II and III list the experiments conducted in part 1 , part 2 and part 3 , respectively. Since studies in part 2 and part 3 involve cable joints, the cable length for all experiments is fixed at $300 \mathrm{~m}$ for consistency.

The number of joining in this study is limited to 2 joints and number of degraded sections is limited to 2 sections. In the following explanations, the term used to represent undegraded cable or good cable is called GC while degraded cable or bad cable is called BC. All cable joints are undegraded joints or good joints called GJ. All experiments are conducted at the velocity of propagation, $\mathrm{Vp}$ of $84.3 \mathrm{~m} / \mu \mathrm{s}$ which is the Vp of the signal travelling in XLPE cable [20].

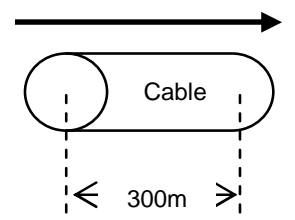

Fig. 1 300m XLPE cable without joint

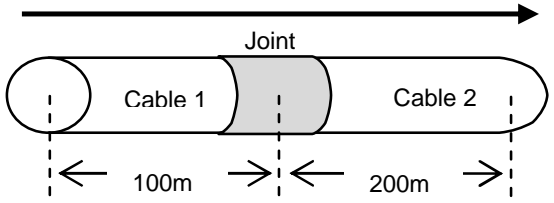

Fig. 2 300m XLPE cable with 1 joint

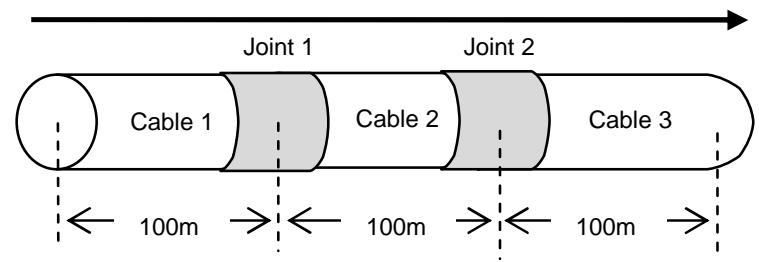

Fig. 3 300m XLPE cable with 2 joints
TABLE I

EXPERIMENTS WITHOUT CABLE JOINT (PART 1)

\begin{tabular}{|c|l|}
\hline Experiment & \multicolumn{1}{|c|}{ Cable Configurations } \\
\hline 1 & $300 \mathrm{~m}$ un-degraded cable $(\mathrm{GC})$ \\
\hline 2 & $300 \mathrm{~m}$ degraded cable $(\mathrm{BC})$ \\
\hline 3 & $200 \mathrm{~m}$ un-degraded cable $(\mathrm{GC})$ \\
\hline 4 & $200 \mathrm{~m}$ degraded cable $(\mathrm{BC})$ \\
\hline 5 & $100 \mathrm{~m}$ un-degraded cable $(\mathrm{GC})$ \\
\hline 6 & $100 \mathrm{~m}$ degraded cable $(\mathrm{BC})$ \\
\hline
\end{tabular}

TABLE II

EXPERIMENTS WITH ONE CABLE JOINT (PART 2)

\begin{tabular}{|c|c|}
\hline Experiment & Cable Configurations \\
\hline 7 & $100 \mathrm{~m}$ GC joint to $200 \mathrm{~m} \mathrm{GC}$ \\
\hline 8 & $100 \mathrm{~m} \mathrm{GC}$ joint to $200 \mathrm{~m} \mathrm{BC}$ \\
\hline 9 & $100 \mathrm{~m} \mathrm{BC}$ joint to $200 \mathrm{~m} \mathrm{GC}$ \\
\hline
\end{tabular}

TABLE III

EXPERIMENTS WITH TWO CABLE JOINTS (PART 3)

\begin{tabular}{|c|l|}
\hline Experiment & \multicolumn{1}{|c|}{ Cable Configurations } \\
\hline 10 & $\begin{array}{l}100 \mathrm{~m} \mathrm{GC} \text { joint to } 100 \mathrm{~m} \mathrm{GC} \text { and } 2^{\text {nd }} \text { joint to } \\
100 \mathrm{~m} \mathrm{GC}\end{array}$ \\
\hline 11 & $\begin{array}{l}100 \mathrm{~m} \mathrm{GC} \text { joint to } 100 \mathrm{~m} \mathrm{GC} \text { and } 2^{\text {nd }} \text { joint to } \\
100 \mathrm{~m} \mathrm{BC}\end{array}$ \\
\hline 12 & $\begin{array}{l}100 \mathrm{~m} \mathrm{GC} \text { joint to } 100 \mathrm{~m} \mathrm{BC} \text { and } 2^{\text {nd }} \text { joint to } \\
100 \mathrm{~m} \mathrm{GC}\end{array}$ \\
\hline 13 & $\begin{array}{l}100 \mathrm{~m} \mathrm{BC} \text { joint to } 100 \mathrm{~m} \mathrm{GC} \text { and } 2^{\text {nd }} \text { joint to } \\
100 \mathrm{mC}\end{array}$ \\
\hline 14 & $\begin{array}{l}100 \mathrm{~m} \mathrm{BC} \text { joint to } 100 \mathrm{~m} \mathrm{BC} \text { and } 2^{\text {nd }} \text { joint to } \\
100 \mathrm{~m} \mathrm{GC}\end{array}$ \\
\hline 15 & $\begin{array}{l}100 \mathrm{~m} \mathrm{GC} \text { joint to } 100 \mathrm{~m} \mathrm{BC} \text { and } 2^{\text {nd }} \text { joint to } \\
100 \mathrm{~m} \mathrm{BC}\end{array}$ \\
\hline
\end{tabular}

Results from experiments in Table 1, 2 and 3 are compiled and analyzed to study the effects of GC and BC at different lengths and influence of cable jointing on the TDR pulse reflections.

\section{RESULTS AND DISCUSSIONS}

Experiments in this study are conducted according to the sequence of part 1, part 2 and followed by part 3 experiments. Every experiment in part 1 comprises of a single cable without any cable jointing. This part of the study focuses on the investigation of the cable degradation influence on the TDR results. Experiments are conducted using three different cable lengths which are $300 \mathrm{~m}, 200 \mathrm{~m}$ and $100 \mathrm{~m}$ cables. For every cable length, two cables are tested where one is having good cable insulation while the other is having insulation degraded condition. By comparing the TDR results from two cables with the same length but in different condition, if differences can be observed in the degraded cable TDR result, this will indicate that degradation in the cable insulation can be identified through this TDR technique. 
Fig. 4, Fig. 5 and Fig. 6 show the results from part 1 which compare the TDR reflections from a good cable to a bad cable of $300 \mathrm{~m}, 200 \mathrm{~m}$, and $100 \mathrm{~m}$ in length, respectively. In Fig. 4, it is clearly observed that the signal injected into the $300 \mathrm{~m}$ good cable of experiment 1 is reflected exactly at $300 \mathrm{~m}$ which is consistent with the actual cable length. The signal injected into a $300 \mathrm{~m}$ bad cable from experiment 2 , however, is reflected at a distance further than $300 \mathrm{~m}$. The experiment is repeated using $200 \mathrm{~m}$ cables by comparing results from experiment 3 and experiment 4 as shown in Fig. 5. Followed by is the comparison of $100 \mathrm{~m}$ cables from experiment 5 and experiment 6 as shown in Fig. 6. Results illustrated in Fig. 5 and Fig. 6 are consistent with results in Fig. 4 where the endpoint reflection of a good cable is detected accurately at $200 \mathrm{~m}$ and $100 \mathrm{~m}$, respectively while the $200 \mathrm{~m}$ and $100 \mathrm{~m}$ bad cables endpoints are reflected at distances further than $200 \mathrm{~m}$ and $100 \mathrm{~m}$, respectively.

These results imply that a cable where its insulation is degraded causes a certain delay to the signal travelling along the cable. Therefore, the endpoint reflection of a degraded cable is not reflected accurately. Hence, this delay indicates that the signal propagating in a bad cable is travelling at a slower velocity of propagation, Vp compared to a good cable. This further supports the findings in [20] through equation (1) where a signal propagates in a good cable at $84.3 \mathrm{~m} / \mu$ s while a signal propagates slower in a degraded cable which can be calculated to be at $79.0 \mathrm{~m} / \mu \mathrm{s}$ :

$$
\begin{aligned}
& \left(\frac{v / 2}{\text { aablelength }}\right)_{\text {minal }}=\left(\frac{v / 2}{\text { aablelength }}\right)_{\text {mamwat }} \\
& \left(\frac{v / 2}{3000}\right)_{\text {aetual }}=\left(\frac{843}{3200}\right)_{\text {mearutad }} \\
& v / 2_{\text {emas }}=790 \mathrm{~m} / \mu \mathrm{s}
\end{aligned}
$$

This TDR technique is studied further by conducting experiments listed in part 2 where these experiments involve a cable joint. This second part of the study looks into the influence of cable joint on the TDR result. Fig. 7 shows the comparison of good cable without any joint from experiment 1 and good cable from experiment 7 in part 2 of this research which has a cable joint. By analysing results in Fig. 7, experiment 7 result clearly shows a pair of reflections at $100 \mathrm{~m}$ which comprises of a positive peak followed by a negative peak with the same magnitude while there is no other reflection observed along the cable from experiment 1 . Hence, this analysis shows that a joint along the cable can be identified from this pair of reflections using TDR technique. In addition, the peaks of these two reflections are observed to have equal magnitude when the cable conditions before and after the joint are the same.

The observation in Fig. 7 is further investigated by comparing TDR reflections of cable configurations from experiment 7 and experiment 8 which is illustrated in Fig. 8. It is again clearly observed that both cable configurations give a pair of reflections at the $100 \mathrm{~m}$ of the cable since both cable arrangements have a joint at the $100 \mathrm{~m}$ of the total $300 \mathrm{~m}$ length cable. However, the result of experiment 8 shows a higher negative peak magnitude compared to experiment 7. It can be assumed that this is due to the condition of the cable insulation since the only parameter that changes is the second cable section of experiment 8 where it is a degraded cable whereas in experiment 7 is a good cable.

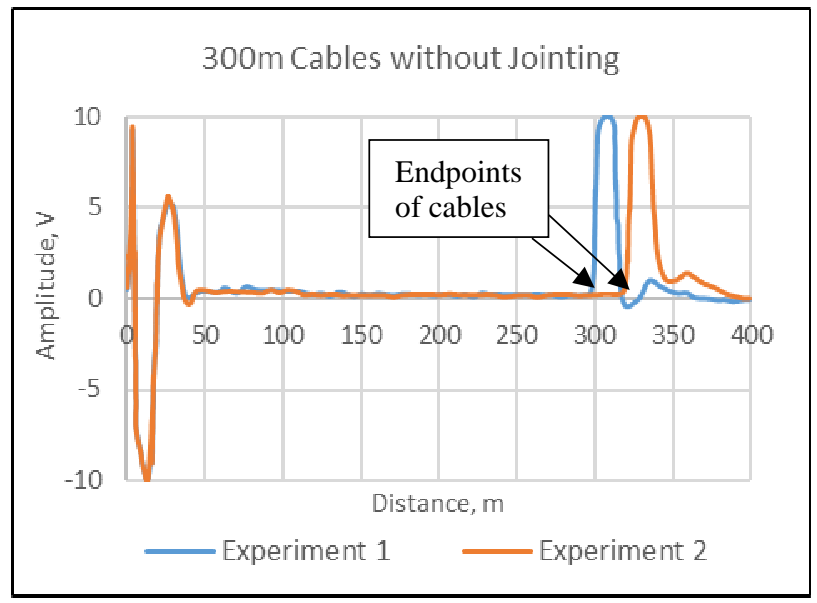

Fig. 4 Results of experiment 1 against experiment 2

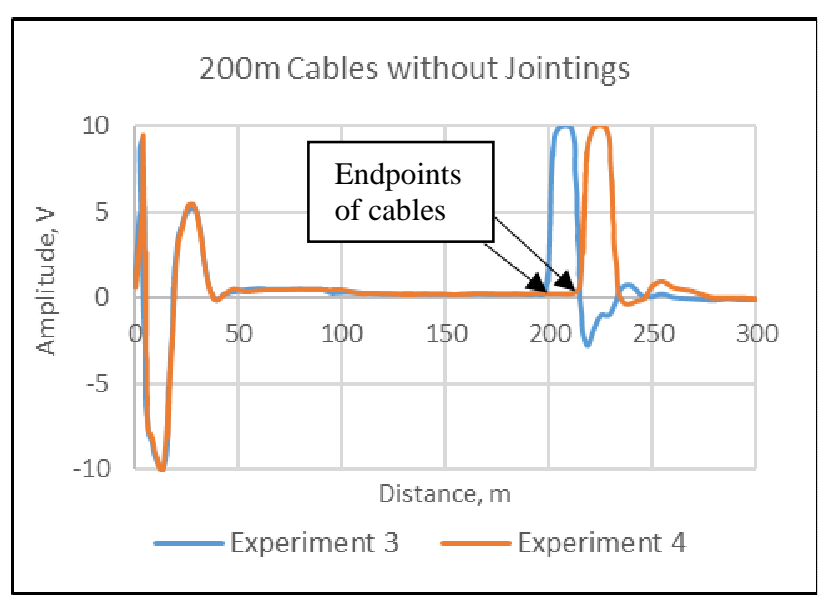

Fig. 5 Results of experiment 3 against experiment 4

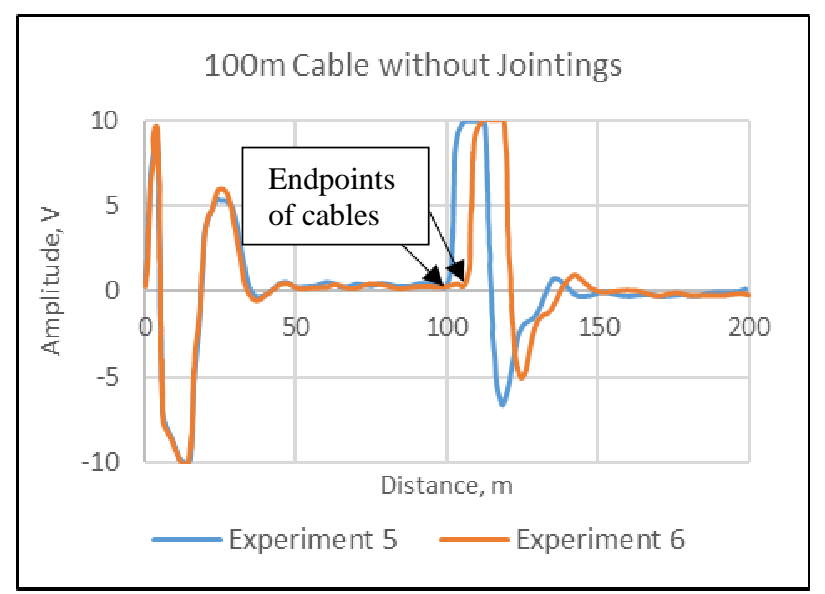

Fig. 6 Results of experiment 5 against experiment 6

Following the earlier assumption made, the degraded section along the $300 \mathrm{~m}$ cable of experiment 8 can be identified and pinpointed at the second section of the cable by applying the observation from part 1 of this research where the signal is reflected with a certain delay for a 
degraded cable. By analysing experiment 8 result from Fig. 8 , the first section of the cable shows no delay since the reflection of the joint is detected at $100 \mathrm{~m}$ accurately, but the delay is observed at the endpoint of cable from experiment 8 . This indicates that the degraded section does not occur before the joint but is observed after the joint since the delay is shown at the endpoint. Therefore, it is concluded that the second section of the cable is degraded. This also proves the findings from part 1 experiments where a degraded cable shows a delay in its reflection. Furthermore, experiments in Fig. 8 show that the condition of the cable can be identified by evaluating the magnitude of the joint reflection beside the delay of the reflections. In order to support this hypothesis, another comparison is conducted where the result from experiment 7 is compared to the result from experiment 9 as shown in Fig. 9.

The TDR result from experiment 9 clearly shows a delay in the first section of the cable while having a higher magnitude of the positive peak than the negative park at the joint reflection compared to experiment 7 . By applying the earlier hypotheses, it can be assumed that the first section of this cable is degraded due to the delay in the joint reflection. Besides that, the higher positive peak reflection also indicates that the first section of cable from experiment 9 is degraded. The second cable section of experiment 9 can be assumed to have a good cable condition since there is no further delay at the endpoint and the magnitude of the negative peak at the jointing did not increase either. Comparing the cable configurations based on an assumption from earlier hypotheses to actual cable configuration, they turn out to be the same. Hence, these observations have proven the earlier hypotheses made from the results in Fig. 8.

Thus, it can be concluded that in the occasion where the two cable sections do not have the same condition, it influences the reflections of cable joint where the reflection of joint nearest to the degraded cable will have a higher magnitude compared to the good cable. Besides that, a delay in the reflection will be observed if the cable insulation at that particular section is degraded.

In the real power system network, electricity is distributed from places far apart which requires very long cable (more than $1 \mathrm{~km}$ ). However, the maximum length of cable in a drum is only $500 \mathrm{~m}$ and thus, requires a few cable joints to fulfil the needed cable length. In order to replicate the actual condition of the power system network, part 3 of this research studies the effect of having 2 cable joints on the TDR reflections. Since this study sets the cable length to be constant at $300 \mathrm{~m}$, the original $300 \mathrm{~m}$ cable is divided into 3 sections of equal length at $100 \mathrm{~m}$ each with 2 cable joints as illustrated in Fig. 3. Since there is more than one cable joint along the cable, six different cable configurations which cover various combinations of good and bad cables have been identified as listed in Table III to further investigate the accuracy of the earlier hypotheses made.

The cable from experiment 10 comprises of three sections of good cables with two good joints. Hence, it is taken as the reference cable to be compared with the other five cable configurations for part 3 analysis study. Fig. 10 compares the cable from experiment 10 with the cable configuration from experiment 11. By observing the results, the two joints are detected at $100 \mathrm{~m}$ and $200 \mathrm{~m}$ accurately for both cables.
There is no delay observed at both cable joints reflections which indicates that the first two cable section for experiment 11 are good cables. The first cable joint reflection for experiment 11 also shows same magnitudes for both positive and negative peaks. However, a delay is observed at the endpoint of the cable from experiment 11 . The negative peak magnitude at the second joint reflection for experiment 11 is observed to be higher than its positive peak magnitude. Applying the hypothesis from part 2 of this study, it can be assumed that the degraded section occurs at the third section of this cable due to the higher negative peak at the second joint and the delay at the endpoint of the cable. The first two sections can be assumed as un-degraded cables since there is no delay detected and the magnitudes of the two peaks at the first joint do not show a significant difference. Comparing this assumption to the actual cable configuration, it is proven to be the same. Hence, the earlier hypotheses are again proven to be true.

Another set of cable configuration is analysed as shown in Fig. 11. Fig. 11 compares the cable configuration from experiment 12 to the reference cable from experiment 10 . The cable configuration of experiment 12 is analysed by applying the hypotheses made earlier. The assumption made from these hypotheses will be checked against the actual cable configuration to verify these hypotheses.

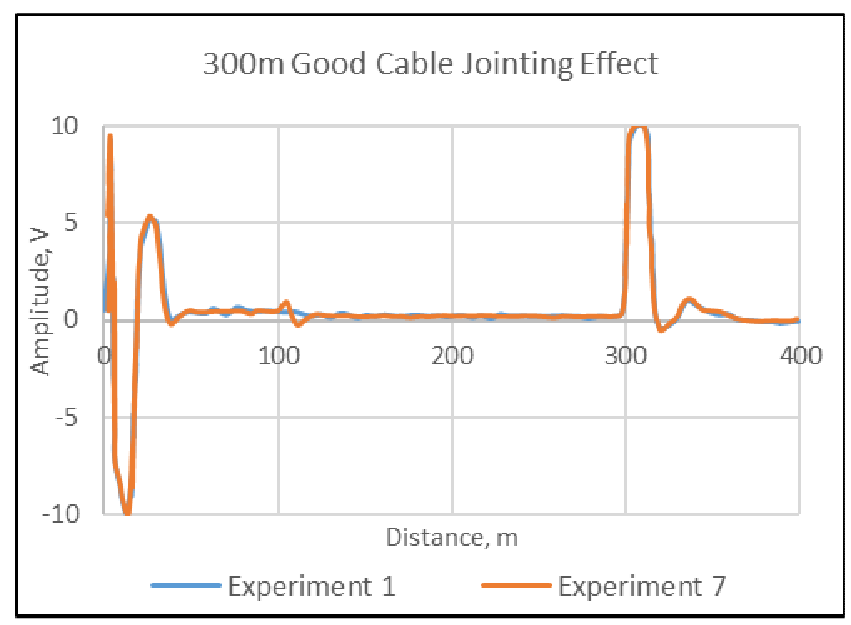

Fig. 7 Results of experiment 1 against experiment 7

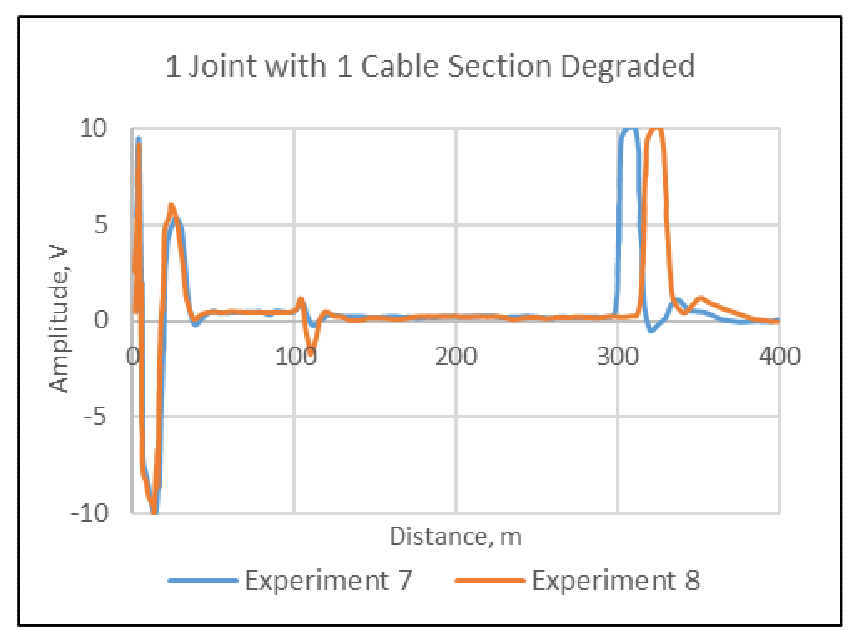

Fig. 8 Results of experiment 7 against experiment 8 


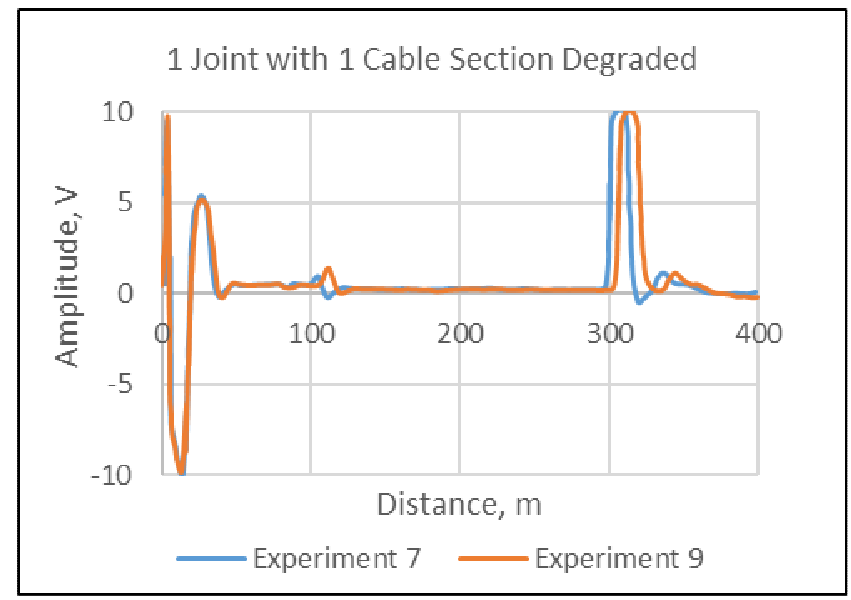

Fig. 9 Results of experiment 7 against experiment 9

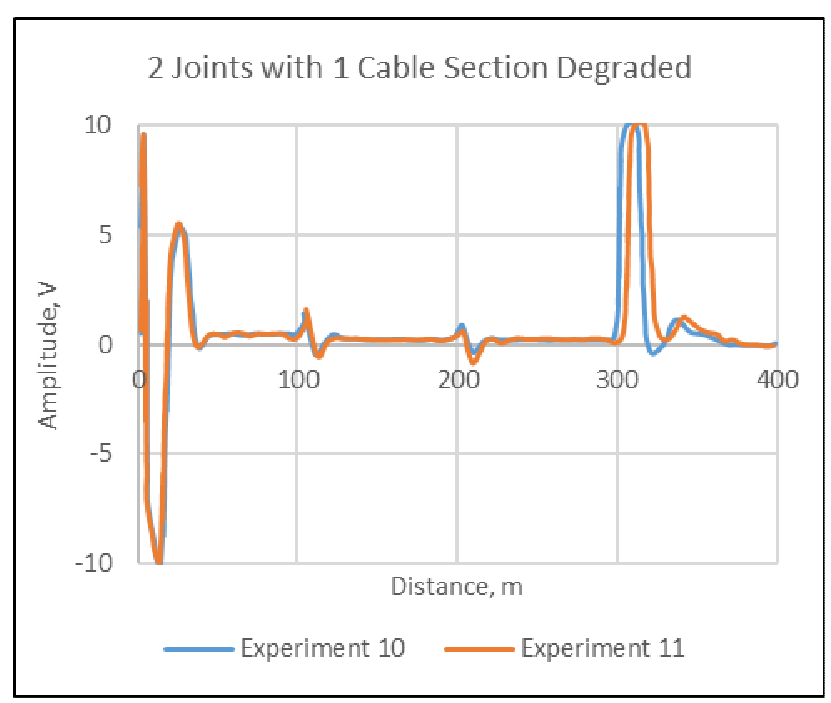

Fig. 10 Results of experiment 10 against experiment 11

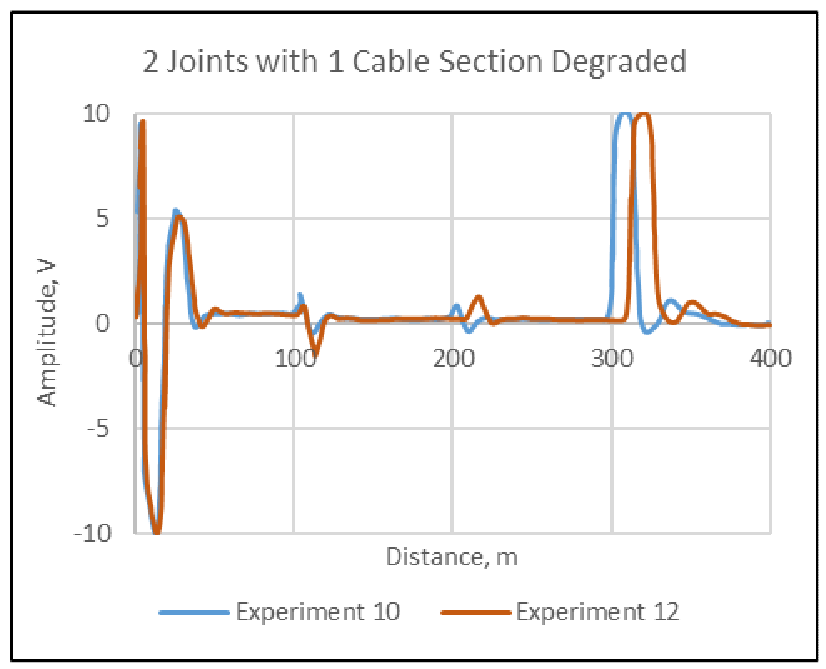

Fig. 11 Results of experiment 10 against experiment 12

Comparing the two TDR results from Fig. 11, experiment 12 shows a delay at the endpoint of the cable which indicates that this set of cables contains degradation. In order to identify the exact degraded cable section, the two hypotheses are applied. The reflection of the first cable joint does not show any delay. Therefore the first cable section can be assumed to be a good cable. However, the negative peak of the first joint reflection shows a higher magnitude compared to its positive peak. Hence, it is possible that the second cable section is degraded. Looking at the reflection of the second joint, it is clearly observed that the second joint reflection is delayed and at the same time, the positive peak magnitude is higher than its negative peak magnitude. This further implies that the second cable section is degraded. Since there is no further delay observed at the endpoint of the cable, hence, the third cable section is assumed to be undegraded. Comparing these cable assumptions to the actual cable configuration, they turn out to be correct again.

After conducting a number of experiments, these hypotheses have been verified to be true for cable configurations up to two cable joints with one degraded cable section. However, in the real case, there could possibly be more than one degraded section along the cable. Hence, more investigations have to be carried out to verify these hypotheses for cable configurations with more than one degraded sections along the cable.

For investigation of cables with more than one degraded cable section, cable from experiment 10 is again taken as the reference cable since it comprises of good cables and good joints.

Fig. 12 compares the results of experiment 10 and experiment 13. Delay at the endpoint of cable from experiment 13 shows that there is degradation of this cable. Observation from the reflection at the first cable joint of experiment 13 shows a delay and the positive magnitude is higher than experiment 10 . This indicates the first section of the cable is degraded. At the second joint reflection, the negative magnitude is observed to be higher than experiment 10 , but there is no further delay observed at the joint. Hence, it can be concluded that the third section of the cable is degraded while the second cable section is un-degraded. The endpoint of experiment 13 is further delayed which further supports the earlier conclusion where the third section of experiment 13 cable is degraded. These assumptions are proven to be correct since the cable conditions are the same as the actual cable configuration.

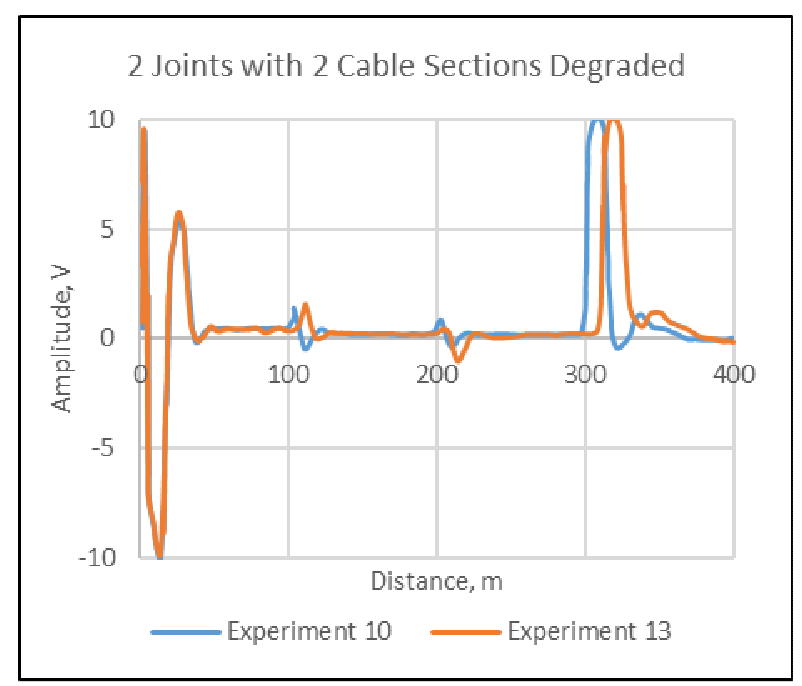

Fig. 12 Results of experiment 10 against experiment 13 
Fig. 13 compares the cables from experiment 10 with experiment 14. An obvious delay is observed at the endpoint which again indicating degradation along this cable configuration. The first joint reflection from experiment 14 shows both peaks with the same magnitude but is delayed compared to experiment 10 . The second joint reflection of experiment 14 is observed with more delay, and the magnitude of the positive peak is higher than the negative peak. The first two cable sections can be assumed to be degraded due to the delay detected at the first joint and further delay observed at the second joint. The magnitude of the two peaks from the first joint is the same which indicates these two cable sections have cable condition, but since a delay is observed at the first joint, therefore these two cable sections are degraded. The third cable section is not degraded since the magnitude of the two peaks from the second joint is not the same. As the magnitude of the negative peak is smaller and no further delay is observed at the endpoint, thus, the third section of this cable is not degraded. The cable analysis is again proven to be the same as the actual cable configuration.

Results from experiment 10 and experiment 15 are compared and illustrated in Fig. 14. The first joint reflection from experiment 15 shows a higher magnitude at the negative peak with no delay observed. This indicates that the first two cables sections do not have the same condition. Since the magnitude is higher on the negative side, this shows that the second cable section is degraded while the first cable section is not degraded. The condition of the second cable section is supported by the reflection from the second joint where a delay is observed. However, the second joint reflection shows both peaks are of the same magnitude. This indicates that there is no change in terms of cable condition for second and third cable sections. Hence, the third cable section is also degraded. Comparing the cable condition analysis based on the hypothesis to the actual cable configuration, both cable conditions are again proven to be the same.

Thus, it is concluded that these hypotheses are correct which can be applied to cable with multiple joints and various combinations of cable conditions.

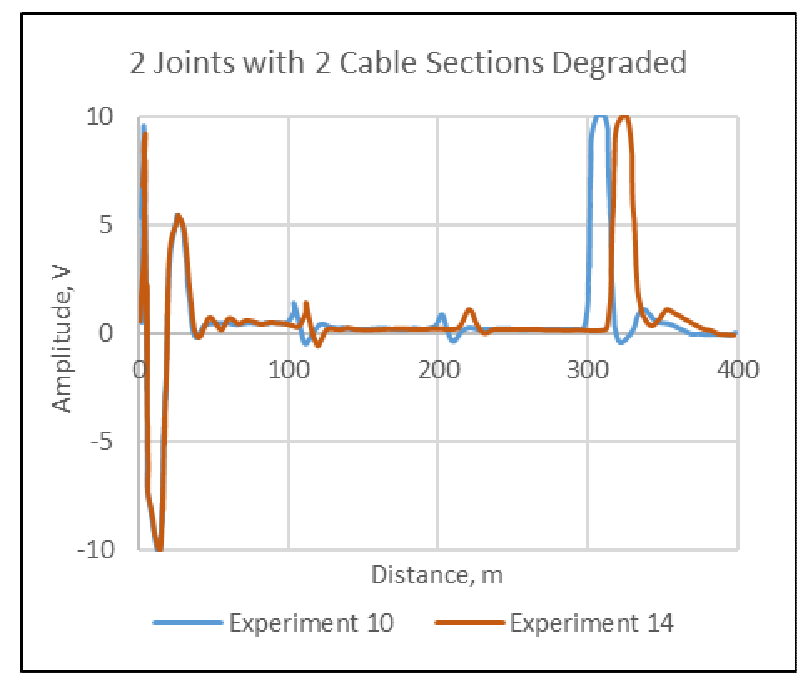

Fig. 13 Results of experiment 10 against experiment 14

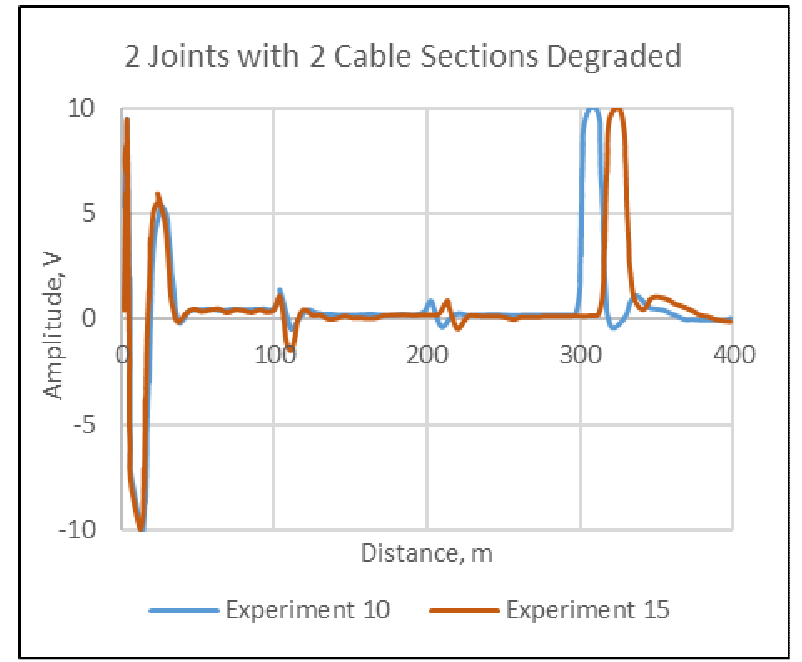

Fig. 14 Results of experiment 10 against experiment 15

\section{CONCLUSIONS}

This study discusses the advancement of TDR potential in detecting the degradation in a power cable and at the same time pinpointing the location of the degradation. This research comprises of a series of experiments in order to be ascertained on the capability of TDR technique in detecting and locating power cable degradation.

The results from experiments in part 1 have shown that a delay in the TDR reflection will be observed if the cable is degraded. This observation is also true when there is a cable joint between these cables. The cable condition before and after a joint can be identified from the cable jointing reflection. Results from part 2 of this study have shown that a good cable joint gives a set of reflections which comprises of a positive peak followed by a negative peak. Results from part 2 and part 3 of this study have proven that the magnitudes of these peaks are the same when the cable before and after the joint have the same condition. These peaks will be reflected with different magnitudes when the cable condition before and after the joint are different. Experiments from this research have shown that the peak nearest to the degraded cable section will have a higher magnitude compared to the other peak.

Apart from observing the cable joint reflection magnitude, a degraded cable can also be identified from the delay observed at the following cable joint reflection or at the endpoint if there is no cable jointing after the degraded cable section. These hypotheses have been verified to be true for cable configuration which comprises of more than one degraded section along the cable. Hence, these hypotheses made in this study are proven correct, and they can be applied to cable with multiple joints and various combinations of cable conditions.

More investigations can be carried out with more than two degraded cable sections along the cable to verify these hypotheses made. Future works can be carried out by replacing the good joint with a degraded joint to study the influence of a degraded joint in the TDR technique results.

\section{ACKNOWLEDGMENT}

The authors would like to thank the Ministry of Education, Malaysia for funding this project under the Fundamental 
Research Grant Scheme (20140121FRGS) and the High Voltage Diagnostics team from TNB Research Sdn. Bhd. for their full support in laboratory facilities, technical support, and cable samples.

\section{REFERENCES}

[1] David L. McKinnon, "Insulation Resistance Profile (IRP) and Its Use for Assessing Insulation Systems," IEEE International Symposium on Electrical Insulation (ISEI), San Diego, pp. 1-4, June 2010.

[2] J. L. Parpal, J. F. Drapeau, C. Potvin, D. Jean, D. Lalancette and P. E. Beaudoin, "Water-Tree Aging Characterization of MV XLPE Cable Insulation using Time Domain Spectroscopy (TDS)," 19th International Conference on Electricity Distribution, CIRED 2007, Vienna, pp. 1-4, May 2007.

[3] Yigang Liu, Xue Chang and Gang Liu, "Analysis of AC Voltage Withstand Test of HV XLPE Power Cable," IEEE International Conference on Solid Dielectrics, Winchester, U.K., pp. 666-668, July 2007.

[4] C. M. Walton, "Detecting and Locating MV Failure Before It Occurs. Experience with live line partial discharge detection on underground paper insulated $11 \mathrm{kV}$ cables in London," International Conference on Electricity Distribution, CIRED 2001, Amsterdam, June 2001.

[5] Katsumi Uchida, Yoichi Kato, Masahiko Nakade, Daisuke Inoue, Hiroyuki Sakakibara and Hideo Tanaka, "Estimating the Remaining Life of Water-Treed XLPE Cable by VLF Voltage Withstand Tests," Asia Pasific IEEE PES Transmission and Distribution Conference and Exhibition, pp. 1879-1884, Vol. 3, October 2002.

[6] Chotimah, Aditya Rianjanu, Bimo Winardianto, Misbachul Munir, Indriana Kartini and Kuwat Triyana, "Electrical Conductivity Improvement of Polyvinyl Alcohol Nanofiber by Solvent Vapour Treatment," International Journal on Advanced Science, Engineering and Information Technology, Vol. 6 (2016) No. 5, pp. 675-681

[7] Mah Sook Yun, Wahidu Zzaman and Tajul A. Yang, "Effect of Superheated Steam Treatment on Changes in Moisture Content and Colour Properties of Coconut Slices," International Journal on Advanced Science, Engineering and Information Technology, Vol. 5 (2015) No. 2, pp. 80-83.
[8] "13 of the largest power outages in history," Union of Concerned Scientist, 8 August 2013.

[9] "Power outages in Jersey City caused by underground cable failure: officials," The Jersey Journal, 21 August 2013.

[10] "NV Energy: Power outage due to underground cable failure," Carson City News, 7 November 2013.

[11] "Downtown power outage caused by cable failure," Raven Radio Foundation, KCAW, 12 November 2013.

[12] "Underground cable failure responsible for power outage in Ballard," Next Door Media, 25 November 2013.

[13] "SMRT points to 3 likely causes of Tuesday's big breakdown," The Straits Times, Singapore, 9 July 2015.

[14] "Cable breakdown may have caused underground blast," John Russell, Indystar, 1 June 2015.

[15] "Power rationing flagged for industry after delay in Basslink power cable repairs," Ellen Coulter and Richard Baines, ABC News, Australia, 14 January 2016.

[16] "Breakdowns force National Grid to issue power supply crunch alert," Emily Gosden, The Telegraph News, U.K., 10 May 2016.

[17] J. Wang, P. E. C. Stone, Y. J. Shin and R. A. Dougal, "Application of joint time-frequency domain reflectometry for electric power cable diagnostics," IET Signal Process, Vol. 4, Iss. 4, pp. 395-405, 4 September 2009.

[18] Yong-June Shin, Edward J. Powers, Tok-Son Choe, Chan-Younh Hong, Eun-Seok Song, Jong-Gwan Yook and Jin Bae Park, "Application of Time-Frequency Domain Reflectometry for Detection and Localization of a Fault on a Coaxial Cable," IEEE Transactions on Instrumentation and Measurement, Vol. 54, No. 6 , pp. 2493-2500, December 2005.

[19] Qinghai Shi, Uwe Troeltzsch and Olfa Kanoun, "Detection and Localization of Cable Faults by Time and Frequency Domain Measurements," 2010 7th International Multi-Conference on Systems, Signals and Devices, Amman, pp. 1-6, 27-30 June 2010.

[20] Tze Mei Kuan, Azrul Mohd. Ariffin, Suhaila Sulaiman and Maria Madelina Bemmynser Sedau, "Improvement in Cable Defects Assessment using Time Domain Reflectometry Technique," Indian Journal of Science and Technology, Vol. 10(4), January 2017. 